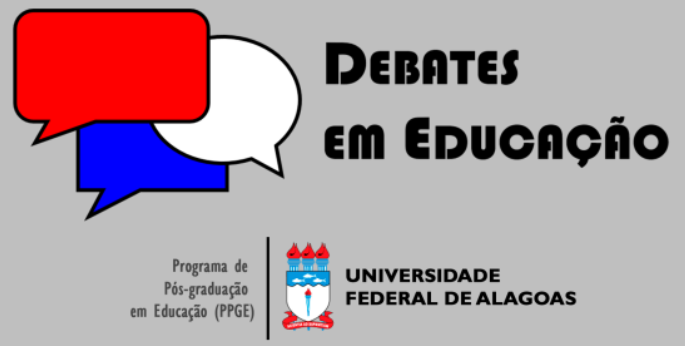

ISSN Eletrônico 2175-6600

Vol. 12 | N. 28 | Set./Dez. | 2020

Aliandra Cristina Mesomo Lira

(9) iD

Universidade Estadual do Centro-Oeste (UNICENTRO) aliandralira@gmail.com

Eliane Dominico

9 iD

Universidade Estadual de Maringá (UEM)

nanedominico@hotmail.com

Débora Ribeiro

9

Universidade Federal do Paraná (UFPR) deboraribeiromsncom@msn.com

Maristela Aparecida Nunes

(9) ID

Universidade Estadual do Centro-Oeste (UNICENTRO) maristelinhanunes@gmail.com

\section{"PRINCESA COME DE BOCA FECHADA": REFLEXÕES FOUCAULTIANAS SOBRE AS PRÁTICAS ALIMENTARES NA EDUCAÇÃO INFANTIL}

\section{RESUMO}

O objetivo do artigo é problematizar aspectos relacionados à alimentação infantil das crianças com atenção para as relações estabelecidas. Parte do pressuposto de que a alimentação carrega consigo uma gama de valores culturais, sociais, afetivos e comportamentais construídos historicamente e, quando vividos institucionalmente pelas crianças pequenas, produzem impactos na constituição de suas subjetividades. Trata-se de pesquisa qualitativa, de cunho exploratório, com coleta de dados em uma instituição pública de Educação Infantil de uma cidade de médio porte da região centro-sul do Paraná, por meio de observações e fotografias. A reflexão, ancorada na perspectiva foucaultiana, nos ajudou a compreender que a alimentação está impregnada pela dinâmica do controle dos corpos infantis, por meio de relações de dominação que desconsideram o respeito devido às crianças pequenas.

Palavras-chave: Alimentação. Crianças. Relações de poder.

\section{"PRINCESS EATS WITH A MOUTH SHUT": FOUCAULTIAN REFLECTIONS ON FOOD PRACTICES IN CHILDHOOD EDUCATION}

\section{ABSTRACT}

The aim of the article is to problematize aspects related to infant feeding in children with attention to established relationships. It starts from the assumption that food carries with it a range of cultural, social, affective, and behavioral values historically constructed and, when lived institutionally by young children, produce impacts on the constitution of their subjectivities. This is a qualitative, exploratory research, with data collection at a public institution of Early Childhood Education in a medium-sized city in the South-central region of Paraná, through observations and photographs. The reflection, anchored in the Foucaultian perspective, helped us to understand that eating is impregnated by the dynamics of control of children's bodies, through relationships of domination that disregard the respect due to young children.

Keywords: Food. Children. Power relations.

Submetido em: 06/12/2019

Aceito em: 28/06/2020

Publicado em: 18/08/2020

do) http://dx.doi.org/| 0.28998/2 I75-6600.2020v I 2n28p95- I|4 


\section{INTRODUÇÃO}

A alimentação, do ponto de vista biológico e especialmente no período da infância, tem a função de suprir as necessidades nutricionais para o crescimento e o desenvolvimento da criança. $\bigcirc$ ato de se alimentar inicia-se no âmbito familiar, mas com a inserção das crianças pequenas nas instituições educativas ele passou a fazer parte da rotina da Educação Infantil. É nesse espaço que se estabelecem outros vínculos entre as crianças e os alimentos, como, por exemplo, o incentivo à adoção de hábitos alimentares saudáveis e a conscientização sobre os malefícios dos alimentos ultraprocessados para a saúde

As refeições realizadas nos Centros de Educação Infantil, dado o caráter pedagógico desses espaços e momentos, não alimentam apenas o corpo, mas nutrem também as demais dimensões que compõem o ser humano. Nessa relação onde estão implicados, além da comida, palavras, gestos, olhares, permissões e proibições, estão presentes também ações que englobam as emoções, os sentimentos, o prazer, a diversão, as alegrias e frustações. Desse modo, a alimentação carrega consigo uma gama de valores culturais, sociais, afetivos e comportamentais construídos historicamente e vividos institucionalmente, sobre alguns dos quais nos dedicaremos nesse texto. A expressão que inicia o título desse artigo traduz, em partes, os achados e entendimentos sobre os quais refletimos.

Dada a importância da alimentação no ambiente educacional, o objetivo dessa pesquisa foi problematizar aspectos relacionados à alimentação infantil das crianças em um Centro Municipal de Educação Infantil de um munícipio de médio porte da região centro-sul do Paraná. Metodologicamente, trata-se de pesquisa qualitativa, com estudo de caso, em que partimos de um estudo teórico que possibilitou um olhar mais aprofundado para as observações realizadas nas turmas do Infantil II e III, durante dois meses do ano de 2019, com anotações em diário de campo, bem como fotografias dos alimentos oferecidos.

O artigo está organizado em três seções. Em um primeiro momento, tratamos da alimentação infantil, os sentidos que adquire no processo de educar e cuidar e seu papel na vida da criança. $\mathrm{Na}$ sequência, abordamos a alimentação nos contextos educativos e como esses momentos e as ações envolvidas atuam na constituiçã̃o da subjetividade das crianças. Posteriormente, apresentamos os dados coletados e refletimos sobre as práticas instituídas e seus impactos na constituição das crianças.

\section{A ALIMENTAÇÃO NO PROCESSO DE EDUCAR E CUIDAR: SENTIDOS E SIGNIFICADOS}

As práticas sociais são reveladoras das formas de organização da sociedade e carregam consigo um conjunto de sentidos e significados. Segundo Carneiro (2005, p. 7I-72), 
[...] comer não é um ato solitário ou autônomo do ser humano; ao contrário, é a origem da socialização, pois, nas formas coletivas de se obter a comida, a espécie humana desenvolveu utensílios culturais diversos, talvez até mesmo a própria linguagem. O uso do fogo há pelo menos meio milhão de anos trouxe um novo elemento constituidor da produção social do alimento. A comensalidade é a prática de comer junto, partilhando (mesmo que desigualmente) a comida, sua origem é tão antiga quanto a espécie humana, pois até mesmo espécies animais a praticam. A diferença entre a comensalidade humana e a dos animais é que atribuímos sentidos aos atos da partilha e eles se alteram com o tempo.

Assim, nos encontros cotidianos promovidos pelos momentos de alimentação, a socialização aparece como articuladora. Isso é visível desde a elaboração dos pratos, quando o alimento, produto bruto, transforma-se em comida, ou seja, o próprio ato de preparar as refeições torna-se uma atividade carregada de simbologia e socialização.

Lima, Neto e Farias (2015) registram que a alimentação assume uma atitude biológica, mas também inclui um comportamento cultural, pois adquire uma importância simbólica. Nessa compreensão, reconhecem que, ao comer, estabelecemos vínculos com os alimentos e com as pessoas envoltas na comensalidade. Do ponto de vista cultural, o que comemos ou deixamos de comer e como fazemos isso são parte da totalidade que nos envolve. Segundo os referidos autores (20 | 5, p. 5 | 4),

[...] a comida, que é o alimento transformado pela cultura, passa a possuir também a função agregadora para os seres humanos. A essa função se dá o nome de 'comensalidade', que tem como significado a capacidade de estabelecer relações de sociabilidade importantes, pois implica reunir as pessoas em torno da mesa. Ou seja, enquanto come, o grupo tem também a oportunidade de dialogar e trocar experiências do cotidiano.

Neste entendimento, Piotto, Ferreira e Pantoni (2006) também reconhecem que a comida tem um significado social, uma vez que comer é uma maneira de se relacionar com os outros. As autoras lembram que não comemos apenas para matar a fome, mas também para festejar, cultuar, despedir-se, ou seja, geralmente os momentos de alimentação entre os seres humanos envolvem a coletividade, com quem comemos. Segundo Maciel (200 I, p. I50),

[...] o com quem envolve partilha, comensalidade, o que transforma o ato alimentar em um acontecimento social. A palavra companheiro (como no francês compagnon e no inglês companion) provém de cum panem, 'os que compartilham o pão'. Assim, a comensalidade, o 'comer juntos', é o momento de reforçar a coesão do grupo, pois ao partilhar a comida partilham sensações, tornando-se uma experiência sensorial compartilhada.

Com as crianças pequenas, em contextos educativos institucionalizados, as práticas de alimentação são consideradas pedagógicas, pois fazem parte do processo de educação e cuidado. A Educação Infantil representa um momento privilegiado de aprendizagens e desenvolvimento, cujas experiências precisam ser planejadas e estruturadas, a partir da compreensão da necessária indissociabilidade entre cuidar e educar. A esse respeito diz Angotti (2014, p. 25):

[...] olhar a Educação Infantil, enxergá-la em sua complexidade e sua singularidade significa buscar atendê-la em sua característica de formação de crianças entre 0 e 6 anos de idade, constituindo espaço e tempos, procedimentos e instrumentos, atividades e jogos, experiências, vivências... em 
que o cuidar e o educar possa prover condições de cuidado, respeitando as crianças em suas inúmeras linguagens e no seu vínculo estreito com a ludicidade.

Logo, a alimentação não pode ser olhada e praticada apenas como uma ação assistencialista, ligada à saúde da criança, pois a forma como é feita e organizada sustenta-se em concepções de educação da criança, ou seja, os alimentos ofertados. $\bigcirc$ espaço para as refeições, as dinâmicas de alimentar-se e alimentar a criança trazem imbuídos princípios éticos, políticos e estéticos, como indicam as Diretrizes Curriculares Nacionais para a Educação Infantil (BRASIL, 2009).

Assim, desde o espaço físico, os utensílios utilizados, a apresentação e oferta da comida, as relações estabelecidas nesses momentos, tudo ensina e tem impacto na construção da identidade e das subjetividades infantis. Por exemplo, se a criança tem autonomia para se servir, conversa com os colegas durante as refeições, interage, participa de um processo formativo com importantes implicações para sua vida e vivência como sujeito numa formação harmonizadora. Por outro lado, se recebe a comida já servida no prato, se este for de plástico, se ela comer numa mesa sem toalha ou guardanapo, se ao acabar a refeição deve abaixar a cabeça e ficar quieta sem conversar, temos encaminhamentos e relações que anulam suas capacidades e limitam as possibilidades de aprendizado que poderiam advir desses momentos.

Barbosa e Quadros (2017, p. 48) refletem sobre as aprendizagens cotidianas e sua dimensão curricular, questionando por que são adotadas certas maneiras e posturas em detrimento de outras: "é preciso reverter esse silenciamento sobre as aprendizagens relativas às vidas concretas das crianças pequenas e defini-las como aprendizagens cotidianas de valor curricular, a serem realizadas também na escola".

Assim, ao comer, dormir, brincar, dentre tantas ações, as crianças aprendem e se desenvolvem em múltiplos aspectos e têm respeitados seus direitos, como pontua Barbosa (20 I8). Segundo a autora, (2018, p. 10), para que as instituições propiciem aprendizagens para as crianças, precisam ofertar "[...] tempo e espaço para que elas convivam; brinquem; participem; explorem; se expressem e conheçam-se"

Vitor e Lira (2019, p. 127) consideram os momentos de alimentação como situações privilegiadas para a formação humana.

O espaço físico, os equipamentos e materiais e os profissionais, pelas relações que estabelecem, podem construir um ambiente de aprendizagens e conquistas. Além de ter contato com diferentes texturas, sabores e aromas, as crianças precisam vivenciar a alimentação como um ato social de trocas, interações e aprendizados nos mais variados aspectos.

Essa compreensão, por parte do professor, o coloca como observador e acompanhante dos tempos das crianças, seus interesses, curiosidades, cujo percurso para a descoberta é encorajado pelo adulto, junto com os pequenos, num processo dialógico e não impositivo. Diz Barbosa; Quadros (20 I7, p. 64): 
[...] é preciso discutir o currículo como uma resposta à vida cotidiana em sua diversidade, uma resposta criada como perspectiva de longo prazo - valores, saberes, posicionamentos e conhecimentos compartilhados - e, ao mesmo tempo, uma perspectiva centrada nas decisões contextuais, do aqui e agora, a partir da valorização das singularidades, dos tempos vividos e das culturas da infância. Essa conexão entre as esferas macro e micro propicia apoio para o estabelecimento do diálogo, tendo em vista a construção dialogada de uma vida em comum.

A boa alimentação como prática indispensável ao bem-estar e à saúde infantil é preconizada pela Sociedade Brasileira de Pediatria', a qual defende a importância e necessidade de cuidado e planejamento das práticas alimentares das crianças, seja no contexto familiar ou pedagógico, como forma de promover a saúde e prevenir a obesidade infantil. Nas instituições educativas, a alimentação é organizada, do ponto de vista do financiamento e provimento, a partir do Programa Nacional de Alimentação Escolar², voltada para suprir as necessidades nutricionais das crianças que frequentam instituições educativas, fomentando bons hábitos alimentares e reduzindo a evasão escolar.

Frente a essas questões, compreendemos que a alimentação em contextos de educação coletivos representa um aprendizado importante na faixa etária da Educação Infantil, cujo valor está imbricado na própria ação. Alimentar-se pode estar relacionado à satisfação de uma necessidade biológica, mas também representa a possibilidade de convívio, condição comprometida na contemporaneidade pela escassez de tempo para a realização das refeições cotidianas. Como as crianças pequenas passam muitas horas de seu dia em instituições educativas, a alimentação passa a fazer parte desses contextos, reconhecida como uma necessidade vital, possibilidade de aprendizado e oportunidade de estabelecer e fortalecer vínculos, condição que problematizamos na sequência.

\section{AS INSTITUIÇÕES EDUCATIVAS E OS MOMENTOS DE ALIMENTAÇÃO: RELAÇÕES DE PODER E AS SUBJETIVIDADES INFANTIS}

A sociedade é o espaço-tempo no qual vivemos e seu arranjo incide na construção da subjetividade humana. Assim, adultos e crianças são constituídos no cerne das relações sociais. Rose (200।, p. 166) define subjetivação como "[...] um agenciamento heterogêneo de corpos, vocabulários, julgamentos, técnicas, inscrições, práticas [...]" e, ainda, (idem, p. 139): “[...] o nome que se pode dar aos efeitos de composição e da recomposição de forças, práticas e relações que tentam transformar [...] o ser humano em variadas formas de sujeito, em seres capazes de tomar a si próprios como os sujeitos de suas práticas". A construção da subjetividade acontece nas variadas relações humanas e nos diferentes cenários sociais nos quais a vida em sociedade se estabelece (individual, social, cultural, institucional).

\footnotetext{
I Ver www.sbp.com.br.

2 Mais informações sobre o programa podem ser consultadas em www.mec.gov.br.
} 
A partir do pensamento estabelecido por Rose (200I), podemos inferir que o conceito que a sociedade tem de infância e de criança reverbera sobre esse sujeito. $\bigcirc$ enunciado produzido até a modernidade sobre a criança propagou a existência de uma única infância, homogênea, e isso fez com que a sociedade acreditasse na existência de um modelo de criança universal. Essa idealização da infância, de seus modos de ser, pensar e agir, muitas vezes, nos impossibilita de enxergar que as crianças vivem esse tempo da vida de modos diferentes. Podemos correr o risco de naturalizá-la de tal maneira que não sejamos capazes de pensar e olhar as crianças para além do discurso que as qualifica como frágeis, dependentes e sujeitos em construção (BUJES; DORNELLES, 20I 2).

A formação da subjetividade também está associada aos saberes produzidos pelas ciências que são aceitos como regimes de verdade. Por muito tempo, a infância e a criança foram objetos de estudos da medicina e da psicologia do desenvolvimento, com foco nos aspectos físicos, cujos padrões evolutivos poderiam ser estimulados pela educação dos sujeitos infantis. Nesse sentido, o discurso pedagógico, da psicologia infantil e da pediatria, opera e fornece sentidos sobre a infância, com saberes que dão conta deste 'deixar viver'. O intuito é salvar corpos, e forjar a razão, pois a criança torna-se objeto de observação, análise e estudo, sendo que o saber sobre ela sustenta as práticas pedagógicas (FERREIRA, 2000).

Contudo, podemos pensar: sob quais regimes de verdade tem se construído a experiência de ser criança? Como a infância tem se constituído e resistido no interior das teias de poder dessa sociedade liquefeita (BAUMAN, 200I), acentuadamente capitalista? A busca por um modelo idealizado produz, muitas vezes, um saber disciplinar pautado em verdades absolutas que objetivam enquadrar as crianças em uma mesma forma como se todas pensassem e se desenvolvessem da mesma maneira.

A constituição da subjetividade infantil está assinalada pelas racionalidades de governamento criadas na modernidade. Bujes (2002) define governamento a partir dos postulados foucaultianos, como o modo de agir sobre a conduta dos outros, o governo das ações. Problematizar os processos de constituição do sujeito, nessa perspectiva, demanda a negação do sujeito universal, homogêneo, para admitir a pluralidade da vida humana.

Podemos refletir sobre a constituição da subjetividade infantil a partir dos conceitos de poder e de governamento de Foucault (20|4). Sob esse enfoque, percebe-se que as crianças são constantemente formatadas e modeladas por uma série de agenciamentos postos em prática pelas diversas instâncias sociais. Dessa forma, a infância é controlada e construída, seja pela via das instituições educativas, seja por meio dos aparatos midiáticos, campos que representam os principais esteios formativos da contemporaneidade.

Foucault (1995), em sua trajetória intelectual, abordou de maneira recorrente a problemática do sujeito e da subjetividade. $\bigcirc$ autor, em seu ensaio intitulado "O sujeito e o poder" comenta que o grande intuito de seus estudos foi compreender a constituição do sujeito na e pela história. A partir desse olhar, 
podemos nos perguntar sobre quais forças concorrem para estabelecer o modo como os sujeitos se constituem, seus modos de pensar, sua visão de mundo.

Em Foucault (1995), percebemos quanto a noção de governamento - compreendido como toda força que leva um sujeito a mudar de conduta, seja em relação aos outros, seja em relação a si mesmo permeia os processos de constituição da subjetividade dos sujeitos. Direta ou indiretamente, todas as pessoas estão imersas em uma trama complexa de poderes, na qual se constituem enquanto sujeitos sociais.

De acordo com o filósofo, os sujeitos não são dados a priori, isto é, não são definitivos, inalteráveis, estáticos, mas se constroem nas diversas relações e papéis sociais. Nessa perspectiva, trata-se de desnaturalizar o indivíduo e pensá-lo enquanto construção histórico-social. Focalizando a infância a partir dessa linha de pensamento, destacamos que problematizar as formas de construção das crianças ao longo da história requer pensar sobre os processos de subjetivação constituídos nos discursos e nas práticas como campo de exercício do poder.

Em Foucault (1995), a subjetividade humana e os processos de subjetivação associam-se estreitamente às relações de poder, uma vez que é no cerne dessas relações que os sujeitos são produzidos, manipulados e encabeçados. O poder está diluído em todos os cenários sociais e se vale de mecanismos diferenciados para se expandir. Assim, precisamos pensar como esses dispositivos operam nos tempo-espaços infantis para constituírem crianças desta ou daquela maneira.

Adorno (2003, p. 14), ao se referir à formação humana, menciona que essa deveria ter como consequência e principal desempenho "[...] tornar os indivíduos aptos a se afirmarem como racionais numa sociedade racional, como livres em uma sociedade livre". Contudo, nos perguntamos: como ser livre, se a sociedade busca padronizar? Quais forças de poder incidem sobre a subjetividade da criança atualmente?

O olhar que construímos das crianças e sua infância comporta o entrelaçamento de elementos da cultura, do contexto histórico e social. Assim, todo conceito comporta as marcas do contexto no qual foi forjado, orientando modos de olhar para as coisas do mundo e conceber as pessoas. As instituições educativas representam um tempo-espaço que contribui com a constituição da subjetividade infantil, por meio da rotina instituída e da efetivação das práticas pedagógicas. Uma das experiências relevantes no cotidiano dessas instituições são os momentos de alimentação. Essa atividade, refletida a partir do esteio foucaultiano, representa uma sujeição às regras que podem tanto ser libertadoras como culminar no automatismo que restringe o desenvolvimento das crianças.

Apoiadas em Bujes (2002), podemos dizer que nas instituições educativas operam dispositivos pedagógicos, os quais colocam em marcha discursos filosóficos, morais, 'científicos', ao instituir práticas; ao definir a organização do espaço e do tempo; ao orientar decisões pedagógicas e administrativas que afetam a vida das crianças nesses espaços. Como lembra a autora, trata-se de colocar em operação um conjunto 
de tecnologias para pensar e intervir na vida da população infantil. Utilizando como recurso o que Foucault denomina de tecnologias disciplinares, a autora considera que existem modelos para condução da prática pedagógica com o objetivo não de repressão ou constrangimento, mas da produção de subjetividades.

Na mesma linha de pensamento, Larrosa (1994) registra que no vocabulário pedagógico existem muitos termos que aplicam algum tipo de relação do sujeito consigo mesmo, como: autoconhecimento; autoestima; autocontrole; autodisciplina; autorregulação. Tais termos designam aquilo que para nós significa ser humano, uma pessoa, um eu, e se relacionam a uma normatividade vista como inerente aos sujeitos 'normais', equilibrados, portanto, sendo ideal as práticas pedagógicas contribuirem nessa constituição. Assim, as vivências nas creches e pré-escolas permitem às crianças construir uma experiência não apenas do mundo exterior, mas também interior, de si mesmas como sujeitos: eus desejantes; eus sexuados; eus pensantes; eus trabalhadores (LARROSA, 1994; BUJES, 2002).

Temos que considerar, ainda, como afirma Larrosa (1994), que a nossa concepção do que é uma pessoa humana é histórica e culturalmente contingente, assim como nosso modo de nos comportar. Além disso, o ser humano se auto interpreta, por isso, o modo como nos comportamos, como somos, na medida em que se relaciona com a interpretação que fazemos de nós, é histórico e culturalmente delimitado. A experiência de si é que torna possíveis essas relações, ela adota formas singulares de produção. Para Larrosa (1994, p. 42):

[...] a própria experiência de si não é senão o resultado de um complexo processo histórico de fabricação no qual se entrecruzam os discursos que definem a verdade do sujeito, as práticas que regulam seu comportamento e as formas de subjetividade nas quais se constitui sua própria interioridade. É a própria experiência de si que se constitui historicamente como aquilo que pode e deve ser pensado. A experiência de si, historicamente constituída, é aquilo a respeito do qual o sujeito oferece seu próprio ser quando se observa, se decifra, se interpreta, se descreve, se julga, se narra, se domina, quando faz determinadas coisas consigo mesmo etc. E esse ser próprio sempre se produz com relação a certas problematizações e no interior de certas práticas.

Nesse sentido, o tempo e o espaço vivenciados pelas crianças na Educação Infantil, também, as experiências e práticas contribuem para a formação de suas subjetividades, ou seja, a maneira como vão construindo formas de auto entendimento, entremeadas por tecnologias de governamento, orienta sua percepção e ação no mundo e consigo mesmas. A problematização que fazemos, diante da pesquisa realizada, é sobre quais mecanismos, tecnologias, formas de governamento, discursos, concepções e imaginários permeiam tais tempos-espaços, especificamente os momentos de alimentação das crianças pequenas institucionalizadas e como eles atuam na (con)formação de sujeitos, aspectos que refletimos a seguir a partir da pesquisa desenvolvida. 


\section{PRÁTICAS ALIMENTARES NAS INSTITUIÇÕES EDUCATIVAS E CONDICIONAMENTO}

As reflexões apresentadas nesta seção são resultado de pesquisa qualitativa, caracterizada por estudo de caso em um Centro Municipal de Educação Infantil (CMEI) de uma cidade de pequeno porte, do estado do Paraná. Como metodologia, partimos de um estudo teórico e utilizamos como instrumento de coleta de dados observações de práticas alimentares das turmas do infantil II e III e fotografias. As observações foram realizadas durante o mês de junho e julho de 2019 e registradas em diário de campo.

No projeto arquitetônico do CMEl, o refeitório era para ser em um local aberto, o que dificultaria o acesso e permanência das crianças em dias frios e chuvosos, não correspondendo às suas necessidades e às características do clima local ${ }^{3}$ e, por esses motivos, foi transferido para um outro local. Assim, as refeições das crianças são realizadas em um refeitório adaptado, numa sala que é bastante pequena, localizada distante da cozinha, o que exige que os alimentos sejam levados até lá em recipientes (bacias e panelas), pelas merendeiras ou buscados pelas professoras.

Ao observarmos o cotidiano pedagógico, evidenciamos que a alimentação é o elemento estruturante das rotinas com as crianças, isso, porque foi possível constatar que é a partir desses momentos que todo o restante do dia é organizado. A alimentação segue um cronograma elaborado pela equipe pedagógica da instituição, no qual cada turma tem um horário estabelecido para as principais refeições e lanches: o café da manhã às 8h; o almoço começa a ser servido às 10 h30min; o lanche às I4h e a janta a partir das 15h45min. Cada turma tem uma escala para esses momentos, e as demais atividades devem se encaixar nos intervalos.

Durante a coleta de dados, constatamos que os horários para entrada e saída do refeitório são seguidos à risca pelos profissionais. Assim, qualquer atividade que esteja sendo realizada (brincar, registros no caderno, sono, parque) pelas crianças pode ser interrompida para o cumprimento dos horários de alimentação. A rigidez no cumprimento do horário é evidenciada no relato abaixo.

A turma do Infantil II não tinha terminado o almoço, contudo as crianças do Infantil III já estavam postas em fila na porta do refeitório. As professoras apressam as crianças, passam por aqueles que estavam 'atrasados' ajudando a terminar de comer, assim pegam a colher da mão da criança e passam a manusear, colocando o alimento na boca dos pequenos. Eles precisam mastigar rápido, alguns desistem de comer dizendo que não querem mais (DIÁRIO DE CAMPO, 17/06/2019).

Essa preocupação excessiva com o tempo incide negativamente sobre a prática alimentar e acaba por convertê-la em um fazer apressado, em que o atendimento a uma necessidade física se sobrepõe às

\footnotetext{
3 A instituição foi construída seguindo o modelo de instituição do PROINFÂNCIA, programa do governo federal para financiamento de construção de instituições de Educação Infantil. Há três modelos de estrutura que variam em função do número de crianças a que a instituição se destina e são iguais para todo o Brasil.
} 
interações e trocas que poderiam existir nesses momentos. Apuradas, as crianças comem de modo afoito, não havendo tempo para atentar-se às questões fisiológicas como a boa mastigação, da autonomia para servir-se e escolher os alimentos, da conversa com os colegas sobre a comida ou outros assuntos. De forma aligeirada, não se estabelecem reflexões sobre a importância de uma alimentação balanceada, do valor nutritivo dos alimentos e tampouco existe espaço para incentivar as crianças a apreciar o sabor daquilo que estão ingerindo. Também, acabam ficando de fora os aspectos sociais presentes nos momentos de alimentação, especialmente em grupos, como a conversa com quem está ao lado. Frente a esses encaminhamentos, avaliamos que a alimentação perde o sentido social e o cunho pedagógico que dela poderiam fazer parte.

Como vimos na descrição acima, estabelece-se o que Foucault (2014) entende como governo, que seria agir sobre a conduta do outro, controlar suas ações. Nessa direção, instauram-se relações de poder regidas por um tempo controlado, que exige disciplina e regramento, onde uns vigiam os outros em diferentes aspectos da vida.

Considerando os estudos de Horn (2016), compreendemos que nas instituições educativas, a alimentação das crianças, além de proporcionar o bem-estar, deve favorecer aprendizagens e proporcionar prazer. Na mesma direção, Cavallini e Tedeschi (2006, s.p) ponderam que se alimentar é uma linguagem composta por elementos culturais que vão desde o modo de sentar, os horários, os gostos e preferências, incluindo a culinária típica de cada região e as relações estabelecidas durante as refeições:

[...] todos os seres humanos, e em particular as crianças que estão em contínuo crescimento, têm uma relação vital com a comida. Porém, a comida não é somente alimento, é também uma linguagem, um verdadeiro alfabeto com o qual construímos a nossa relação com os outros e com o mundo.

A partir dos autores, compreendemos que o ato de se alimentar, além de nos nutrir enquanto seres humanos, possibilita um encontro social e afetivo com cheiros, aromas e cores. Entretanto, quando o mais importante é cumprir um horário pré-determinado, desconsiderando as especificidades de cada criança, o espaço educativo desrespeita as singularidades, as diferenças inerentes ao ser humano e a dimensão estética e sensível que permeia o alimentar-se. Naturalmente, não comemos todos no mesmo ritmo, ou os mesmos alimentos, pois trata-se de uma ação cultural cujos fazeres do nosso grupo de origem e convívio incidem sobre nossos modos de ser.

O tempo cronometrado da sociedade capitalista impõe um processo de rotinização escolar forçada que concorre para adaptar os corpos infantis ao modo de operar das outras instituições sociais, cujo funcionamento é adaptado para o tempo da produção, do mercado de trabalho. Nós, adultos, comemos apressados para retornar ao trabalho ou consumidos pelas inúmeras obrigações de nosso dia a dia. Institucionalmente, a rotina se organiza a partir de uma perspectiva adultocêntrica orientada, predominantemente, pelas necessidades dos adultos. 
A forma como cuidamos e educamos as crianças atua na constituição da subjetividade infantil e o privilégio por rotinas mecanizadas impõe à organização papel principal, secundarizando as crianças. A partir dessa compreensão, torna-se importante que os professores reconheçam que as necessidades das crianças são diferentes das suas, que seus tempos precisam ser respeitados para que a alimentação seja um momento de prazer, e não apenas de ingestão de alimentos .(FLACH; SORDI, 2007).

A realidade encontrada nos momentos das refeições das crianças desvelou que esses são constituídos por práticas disciplinares e restritivas. Elas não possuem autonomia para escolher os alimentos, tampouco para servir-se, pois, como mostra a foto a seguir, o prato é colocado já pronto na frente da criança. Como registra Guimarães (20II), potência da imagem dá sentido e visibilidade ao controle dos corpos, pois tal qual as crianças os pratos são enfileirados, todos 'iguais', representam a contenção e são a palavra proferida sem a intervenção verbal direta do adulto.

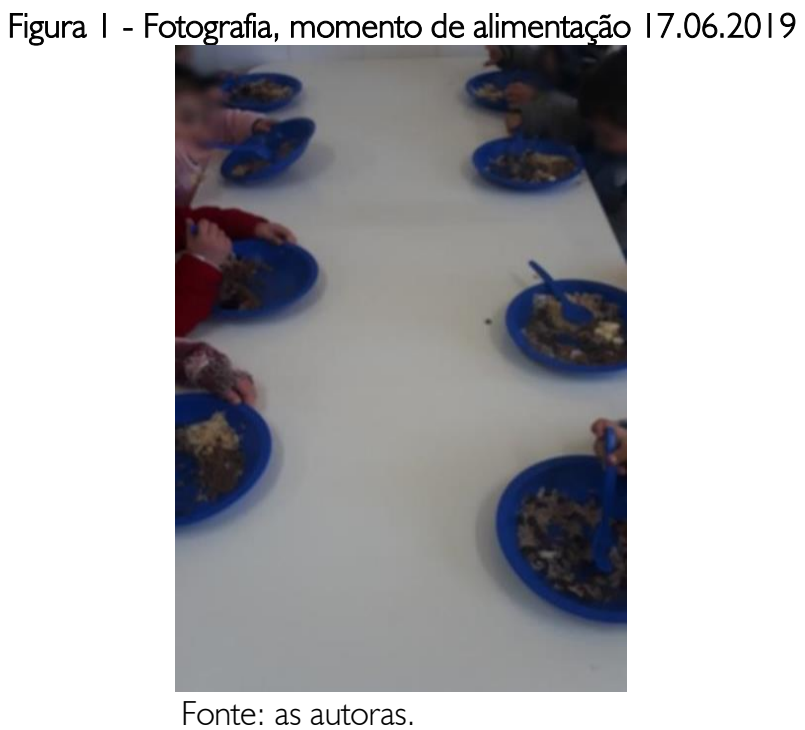

Figura 2 - Fotografia, momento de alimentação 17.06.2019

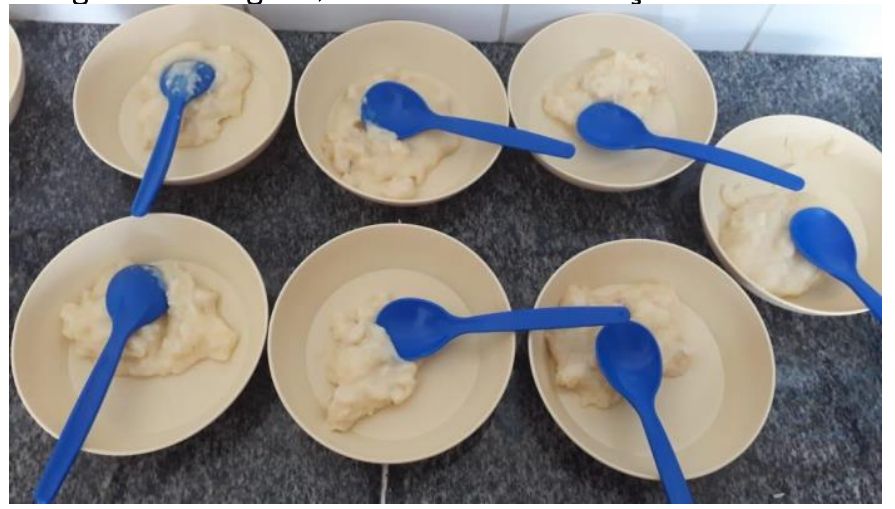

Fonte: as autoras.

Não há adultos na cena, mas a gramática espacial da disposição dos pratos revela lugares marcados. Outros aspectos nos inquietam, como a organização do espaço e os utensílios para as refeições. As paredes do refeitório são na cor branca; os pratos são dispostos em mesas sem toalhas ou guardanapos; as crianças 
sentam em bancos de madeira sem encosto; os pratos e as colheres são de plástico, estas sendo grandes, inadequadas ao tamanho das crianças. Ao adentrar nesse espaço, sentimos ausência do afeto, da recepção calorosa, do diálogo entre as crianças e com os adultos, do respeito e da autonomia. Assim, podemos nos perguntar: onde está a vida que pulsa nesse refeitório? Se em nossa casa sentamos em cadeiras confortáveis, colocamos toalhas nas mesas, utilizamos talheres, selecionamos os alimentos de nossa preferência, por que, ao planejar a alimentação das crianças não pensamos nesses detalhes tão básicos à boa higiene e conforto? Por que o tratamento que oferecemos às crianças difere daquele que damos aos adultos? Quais as condições de humanização nas instituições educativas?

A rotina instituída, os espaços, a condução dos momentos de alimentação e os aparatos utilizados nos revelam que, no âmbito educativo, vigoram pedagogias colonizadoras, uma vez que as ações não são construídas e planejadas para as crianças ou com elas, mas sim sobre elas. Somos tão colonizados na infância que, ao tornarmo-nos adultos e professores de crianças, esquecemo-nos totalmente do que é ser criança afinal. São práticas e teorias colonizadoras, porque buscam o comportamento ideal; colocam em ação um currículo homogêneo, com atividades e encaminhamentos praticamente iguais todos os dias e horários que seguem o modelo fabril, rígidos e inflexíveis.

A julgar pelo cotidiano observado, a criança não é o centro das ações, não é considerada como alguém que pensa, que tem competência para falar de si, do que sente. Pelo contrário, ouvir as crianças passa a ser entendido como 'fazer a vontade dela', e não reconhecida como uma atitude que a respeita. A 'escolha' da criança é tida como um privilégio, coisa a ser evitada nos contextos educacionais. "No café da manhã, a professora passa perguntando: 'pão com doce ou pão sem nada?' Nesse momento entra no refeitório uma professora que estava em hora atividade e fala: 'temos que acabar com essa mania de pão com doce, pão sem doce'" (DIÁRIO DE CAMPO, 25/06/2019).

A uniformização traz embutida a facilidade de lidar, seja com comportamentos, modos de ser e de pensar, e se todos comem do mesmo jeito o previsível se mantém e dá menos trabalho. Barbosa e Quadros (2017, p. 46) lembram que "não raro, alguns professores impacientes, desejosos de alunos proativos, dinâmicos e rápidos, fazem exigências inadequadas e descontextualizadas às crianças".

A refeição que se apresenta como um elemento estruturador da rotina infantil está mergulhada em regras e normas cujo controle atua sobre os corpos, buscando disciplinar, ajustar e docilizar as crianças para a harmonia, o silêncio. Nesse sentido, ao considerar que conforme Franco (2004, p. 25): “[...] os homens comem como a sociedade os ensinou [...], sendo que os hábitos alimentares decorrem da interiorização, desde a mais tenra infância, de regras e de restrições", podemos nos questionar se as práticas alimentares desenvolvidas nas instituições educativas refletem positiva ou negativamente na subjetividade das crianças, buscando compreender quais significados assumem e como são incorporadas pelos pequenos. 
A questão da infância governada pode ser entendida também pelo viés da colonialidade do poder, do ser e do saber explicitada por Quijano (2000). Para o autor, a partir da conquista da América, em I492, instalou-se uma hierarquização mundial pelos critérios de raça, sexo e trabalho. Mesmo com o fim do colonialismo no Brasil, essa mentalidade prevalece, organizando as formas como o trabalho, as relações intersubjetivas, a manutenção das diferentes classes sociais em estratos ordena a vida em geral. Também, as formas de ser e de saber foram hierarquizadas, de modo que os conhecimentos e subjetividades atreladas às identidades subalternizadas, como mulheres, indígenas, negros e crianças, são considerados inferiores. Superiores são os conhecimentos e subjetividades relacionados ao mundo ocidental, ao masculino, heterossexual, pai de família, branco, cristão.

Dessa concepção advém toda uma organização pedagógica que na modernidade se instala nas escolas e creches, com a construção de um arcabouço teórico que se diz neutro e objetivo sobre os outros povos e sujeitos, sobre as crianças inclusive. Assim, como os indígenas americanos foram descritos como ignorantes, bárbaros e incivilizados, as crianças foram consideradas inúteis, sem especificidade própria, tábulas rasas, miniadultos, sem conhecimento e incapazes de produzi-lo, com uma forma de ser incômoda que precisava ser moldada, educada.

No refeitório, percebemos que Pedro se destaca, pois gosta de conversar. Por sua característica, é bem acolhido pelos colegas. Durante o almoço, a professora chama sua atenção, pedindo que pare de falar. Ele fica quieto por alguns instantes e depois retoma os diálogos e risos. A professora, impaciente, retorna até ele e o coloca em uma mesa separada para comer, sozinho. Pedro ${ }^{4}$ fica irritado e resiste (DIÁRIO DE CAMPO, 27/06/20I9).

Barbosa e Quadros (2017, p. 47) lembram que "os adultos demandam das crianças qualidades que nem mesmo eles possuem". Em diversas outras situações, presenciamos reprimendas pelas conversas das crianças entre si, enquanto as professoras falavam de assuntos diversos entre elas. Para as crianças, o autoritarismo assusta, se faz nas falas, num olhar, numa atitude que penaliza, corrige, busca construir comportamentos diferentes daqueles considerados 'desviantes'. Segundo Barbosa; Quadros (2017, p. 49),

[...] o modelo escolar, em geral, não deseja um corpo falante, vibrante, transgressor, atravessado pelo desejo, pois tem como ideal um corpo quieto, fragmentado, vigiado. A criança é sinestésica: movimenta-se, traça rotas, aprende com seus sentidos e, com sua ação, exprime no corpo seus desejos, sentimentos positivos e negativos, suas inquietações, insatisfações. O corpo dos pequenos pensa, fala, expressa e comunica.

Vemos reproduzirem-se, nas creches e escolas, pedagogias que seguem esse pensamento, quando em carteiras as crianças são enfileiradas sem poderem se movimentar ou conversar. Quando não importa o que trazem de conhecimento, de cultura, pois ao professor caberia modificar seu pensamento, aliando intervenções sobre os comportamentos. Nos momentos de alimentação, também existe uma

\footnotetext{
${ }^{4}$ Para efeito de análise, omitimos a identificação da instituição e optamos em manter o nome verdadeiro das crianças, entendendo-as como sujeitos principais da pesquisa.
} 
qualificação de condutas. Barbosa (2006) reconhece a rotina como estruturadora do ambiente e das crianças, padronizando as relações. $\bigcirc$ relato a seguir exemplifica como nos momentos de alimentação a qualificação das condutas é evidenciada.

A turma do Infantil Il chega ao refeitório e a professora determina o local que cada criança deve sentar. Em tom alto vai dizendo: 'Pedro, você não pode sentar aí, pois só fica conversando durante o almoço'. Em seguida pede que as crianças coloquem as mãos sob os joelhos e começa a lançar os pratos com força e rapidez sob a mesa (DIÁRIO DE CAMPO, 17.06.2019).

A partir desse exemplo, segundo Mesomo (2004, p. 42), observa-se durante a prática alimentar a existência de "modos de organização nos quais poder e obediência se articulam, conjugando uma série de dispositivos que levam a um ajuste cada vez mais controlado, por meio de atividades produtivas e desencadeadoras de comportamentos desejáveis". As verbalizações por parte dos profissionais também expressam esse tensionamento.

'Essas professoras não vão mais voltar aqui devido ao mau comportamento de vocês'; 'Pedro, eu vou recolher seu prato'; 'você não pode sentar perto dela, só conversa'; 'no refeitório não é lugar de conversa, e sim de comer' (DIÁRIO DE CAMPO, 26.06.2019).

Fica evidente que, na perspectiva foucaultiana, a prática educativa realizada dessa forma julga, classifica o bom e o mau, o certo e o errado, em nome de uma dinâmica de controle que busca enquadrar o indivíduo por meio de coações e ameaças. Assim, frases coercitivas são repetidas constantemente nesses espaços e produzem sujeitos governados, indo na contramão do que mencionamos anteriormente, de que a comida exerce um fator facilitador de relações e do diálogo. Segundo Foucault (20 | 4, p. | 35), tratase de "[...] uma política das coerções que são um trabalho sobre o corpo, uma manipulação calculada de seus elementos, de seus gestos, de seus comportamentos". Outros enunciados proferidos representam essa dinâmica sobre o corpo infantil, potencializando julgamentos e normatizando ações.

'Princesa come de boca fechada', 'perninha para frente para não cair', 'Senta direito', 'Rafa, sem brincar com a comida, caso contrário eu vou guardar', 'Antony, por que pediu se não cabe na barriga, quando você pedir eu não vou dar' (DIÁRIO DE CAMPO, 17.06.2019).

A partir dessas falas, podemos afirmar que o discurso não apenas reproduz a realidade como a fabrica. Como afirma Louro ( 1997), a linguagem é um campo eficaz e permanente para instituir distinções e desigualdades, pois sua existência no cotidiano é naturalizada. Nessa compreensão, a linguagem não apenas nomeia ou fala das coisas, mas as institui, produzindo e fixando realidades e diferenças. As instituições escolares, desde seu início, operaram no sentido da separação dos sujeitos: dos que tinham direito à escola; dos bons e maus alunos; dos normais e anormais; adultos de crianças; meninos de meninas; ricos de pobres. Por meio de seus códigos, a escola limita o que cada um pode ou não fazer, indica o lugar que cada um deve ocupar, apresenta os modelos a serem seguidos. 
As crianças do Infantil II entram e se sentam no refeitório. O professor começa a servir a refeição nos pratos antes de colocá-los sobre a mesa. Enquanto isso, fala: As meninas, e elas começam a cantar: Sou uma florzinha de Jesus, abro a boquinha para cantar, fecho os olhinhos para rezar. Então o professor fala: E os meninos? E eles cantam: Sou um soldadinho de Jesus, abro a boquinha para cantar, fecho os olhinhos para rezar. Depois o professor conduziu uma oração de agradecimento pelo alimento (DIÁRIO DE CAMPO, 05.07.2019).

As questões religiosas, ao adentrarem nos espaços educativos, apropriam-se de situações educativas para propagar seus dogmas, suas crenças, o que não poderia acontecer. Além disso, o discurso e as práticas vão instituindo e naturalizando comportamentos, vocalizações de controle moral, muitas vezes, já introjetadas pelas crianças: agradecer, sentar sem se mexer, ficar calado, comer, esperar. As crianças que não se enquadram nesses modelos são repreendidas, afastadas do grupo, classificadas como desobedientes, tagarelas, inconvenientes. Durante as observações, foi recorrente presenciar a exclusão dos momentos de alimentação de algumas crianças devido ao seu 'mau comportamento' no refeitório. Além disso, certos lugares eram interditados de antemão, ou seja, cada um em seu assento, direcionado pelo adulto como forma de evitar conversas, condição que gerava nas crianças 'punidas' frustração e ressentimento. Se retomamos a compreensão de que na Educação Infantil o currículo representa um conjunto de práticas pedagógicas, reconhecemos que a alimentação é uma delas e, nesse sentido, Dominico, Lira, Saito e Yaegashi (2020) alertam que o currículo pode atuar como instrumento de governo das crianças.

Vemos como a religião pode atuar juntamente com pedagogias colonizadoras, a fim de moldar comportamentos, formar corpos dóceis, o que historicamente tem ocorrido. Um aprendizado contínuo e eficaz faz penetrar um ritmo, uma cadência, uma disposição física, uma postura, onde os sujeitos, envolvidos por tais mecanismos e práticas, reagem e constituem suas identidades escolares (LOURO, 1997). Essas lições, atravessadas pelas diferenças, também marcam papéis de gênero muito claros em discursos como: sou uma florzinha, sou um soldadinho, princesa come de boca fechada, entre outros. Das meninas se espera o 'bom comportamento', que sejam amáveis, que sentem com as pernas fechadas, sejam recatadas; dos meninos se tolera que sejam viris, espertos, mais bagunceiros.

A despeito dos condicionamentos impostos via escolarização, Foucault (2008, p. 266) considera possível a existência de rotas de fuga, denominadas pelo autor de "contraconduta no sentido de luta contra os procedimentos postos em prática para conduzir os outros, o que faz que eu prefira essa palavra a 'inconduta', que só se refere ao sentido passivo da palavra, do comportamento: não se conduzir como se deve". Essa resistência foi observada em alguns momentos durante as refeições, como explicitado no registro a seguir.

Muitas crianças ignorando as verbalizações dos professores, não se motivam a provar alguns alimentos, até murmuram que não gostam, ficando apenas mexendo a colher no prato como resistência à ordem de comer. Em outro momento, enquanto a docente virava-se para servir as demais crianças, uma delas joga beterraba embaixo da mesa (DIÁRIO DE CAMPO, 25/06/20 I9). 
As ações das crianças condizem com os postulados de Foucault (2008) a respeito do contrapoder, nos quais ele ensina que em toda relação onde há poder, pode existir um antagonismo a ele por meio de questionamentos, ações contrárias, exposição de argumentos. Esses posicionamentos das crianças são, muito vezes, interpretados sob a ótica adultocêntrica como rebeldia, falta de limite, desobediência, quando, na verdade, são uma reação a uma prática autoritária que desrespeita seu ser e sentir. São posturas contrárias a um fazer docente que considera a capacidade infantil de interpretar as situações, de interagir e pensar sobre suas vivências. Ao refletir sobre as rotinas dos bebês na creche Guimarães (201 I, p. |28) lembra:

[...] ela delimita os gestos e movimentos, estabelecendo um quadro por meio do qual os corpos se tornam inteligíveis. A organização do tempo e sua articulação com a distribuição das crianças no espaço, ligadas intimamente com as necessidades biológicas (em especial comer e dormir), modelam e dirigem o corpo. Ao mesmo tempo, percebemos alterações e desvios, principalmente quando focalizamos as crianças e suas trajetórias dentro do tempo planejados pelos adultos.

Assim, as crianças nos mostram que, mesmo estando envoltas em relações de poder, por vezes inconformadas e sem resposta para suas perguntas, encontram saídas nem sempre óbvias. Como afirma Santiago (20|4), os sons que ecoam pela Educação Infantil são muito mais que barulho incompreensível. Por meio de choros, falas e mordidas, as crianças mostram sua resistência à violência dos enquadramentos sociais. A escuta e observação atenciosa das linguagens expressivas na infância traz subsídios para a construção de pedagogias descolonizadoras, para repensarmos a ação docente.

Assim, a Educação Infantil se tornaria espaço de afirmação das diferenças, tomadas como mote pedagógico, espaço de inventividade e protagonismo infantil, promovendo a escuta da criança, de seus modos de ser e estar no mundo, sendo importante ao professor estar disposto a brincar muito com as crianças, como orienta Kramer (2020).

Delorme (2018) problematiza como as experiências com as crianças podem assumir formas criadoras, que incluam conhecer, respeitar e atendê-las como sujeitos únicos, a partir de um escopo mais humanizado com atenção à experiência e ao sentido.

Trata-se de apostar na passagem da criança, universal e única, para uma criança, impessoal, singular e múltipla (ABRAMOWICZ; OLIVEIRA, 20I2) que, a partir de suas relações com os outros e com o mundo, constrói interpretações, pensa e fala de suas experiências. Essa concepção colocada em prática nos momentos de alimentação abriria espaço para a aquisição paulatina da autonomia, para o diálogo que acolhe o outro, para sua forma de ser que se modifica na convivência e pode adquirir novos hábitos, provar diferentes alimentos, dentre outras possibilidades.

Para Carvalho; Sâmia (2016, p. 45), a Educação Infantil que privilegie a escuta das crianças coloca em prática o "[...] elemento da profissionalidade docente que corresponde à habilidade de realizar uma observação atenta, aberta e sensível às atitudes das crianças, interpretando seus sentidos e incorporando 
esses saberes na prática". Uma escuta que permite ao professor compreender o mundo e a visão da criança, com seus pertencimentos, identidades em construção, desejos e necessidades, manifestos também nos momentos em que se alimenta.

\section{5 'JÁ ACABOU, QUEM COMEU, COMEU...'}

As reflexões aqui apresentadas, a partir do cotidiano instituído nas práticas de alimentação com crianças pequenas, nos ajudam a compreender que comer não tem um fim em si mesmo, mas representa uma ação carregada de significados e sentidos, muitos deles instituídos e controlados com vistas à adequação social.

Os momentos de alimentação na Educação Infantil, seja pela forma como são organizados e conduzidos, seja pelo espaço onde ocorrem ou pelos utensílios que utilizam, podem impactar sobremaneira na formação da subjetividade infantil, cujo desejo institucional a quer controlada e submissa. O referencial foucaultiano orientou nosso olhar para essas situações, identificando-as como envoltas em um processo de governamento, que faz uso de tecnologias pedagógicas colonizadoras controladoras dos modos de ser e agir.

É também com Foucault que aprendemos ser possível escapar, resistir ao cotidiano que controla e disciplina, embora, na maioria dos momentos, o poder seja insidioso e permeie o trabalho pedagógico e as relações de maneira naturalizada. Como educadoras, acreditamos ser possível construir espaços educativos e pedagogias para e com as crianças, que as respeitem como seres humanos, fazendo com que a alimentação seja mais uma das possiblidades de crescimento pessoal e coletivo em que prevalece o respeito com o outro e consigo.

\section{REFERÊNCIAS}

ABRAMOWICZ, A.; OLIVEIRA; F. As relações étnico-raciais e a sociologia da infância no Brasil: alguns aportes. In: BENTO, M. A. S. (Org.). Educação infantil, igualdade racial e diversidade: aspectos políticos, jurídicos, conceituais. São Paulo: CEERT, 2012. p. 47-61.

ADORNO, T. A filosofia e os professores. Trad. Wolfgang Leo Maar. In: ADORNO, T. Educação e emancipação. São Paulo: Paz e Terra, 2003. p. 51-74.

ANGOTTI, M. Educação Infantil: para que, para quem e por quê? In: ANGOTTI, M. (Org.). Educação Infantil: para que, para quem e por quê? Campinas, SP: Alínea, 20 I4. p. 15-33.

BARBOSA, M. C. S.; QUADROS, V. da S. R. de. Aprendizagens cotidianas: os cuidados pessoais das crianças como gesto curricular. Em Aberto, Brasília, v. 30, n. 100, p. 45-70, set./dez. 2017. Disponível em: http://rbepold.inep.gov.br/index.php/emaberto/article/view/3358. Acesso em: 19 jun. 2020. 
BARBOSA, M. C. S. A BNCC e os direitos das crianças: Educação Infantil em evidência. Entrevista. Com Censo, Brasília, v. 5, n. 2, p. 9-13, maio 20 I8. Disponível em: http://periodicos.se.df.gov.br/index.php/comcenso/article/view/452/27l. Acesso em: 19 jun. 2020.

BARBOSA, M. C. S. Por amor e por força: rotinas na Educação Infantil. Porto Alegre: Artes Médicas, 2006.

BAUMAN, Z. Modernidade Líquida. Rio de Janeiro: Jorge Zahar, 2001 .

BUJES, M. I. E. A invenção do eu infantil: dispositivos pedagógicos em ação. Revista Brasileira de Educação, Rio de Janeiro, n. 21 , set./out./nov./dez. 2002. Disponível em: http://www.scielo.br/pdf/rbedu/n2I/n2Ia02. Acesso em: 21 set. 2019.

CARNEIRO, H. S. Comida e sociedade: significados sociais na história da alimentação. História: Questões \& Debates, Curitiba, n. 42, p. 7I -80, 2005. Disponível em: https://revistas.ufpr.br/historia/article/view/4640/3800. Acesso em: 19 jun. 2020.

CAVALLINI, I.; TEDESCHI, M. A comida e suas linguagens. Pátio Educação Infantil, Porto Alegre, n.47, abril 20 I6. Disponível em: www.loja.grupoa.com.br/revista-patio. Acesso em: 14 set. 2019.

CARVALHO, M. I. da S. de S.; SÂMIA, M. Aprender a escutar crianças: um dispositivo de formação. Saber \& Educar: Estudos da Criança, Porto, Portugal, n. 21 , p. 40-49, 2016. Disponível em: http://revista.esepf.pt/index.php/sabereducar/article/view/206. Acesso em: 19 jun. 2020.

DOMINICO, E.; LIRA, A. C. M.; SAITO, H. T. I.; YAEGASHI, S. F. R. Práticas pedagógicas na Educação Infantil: o currículo como instrumento de governo dos pequenos. Revista Brasileira de Estudos

Pedagógicos, Brasília, v. I01, n. 257, p. 21 5-234, jan./abr. 2020. Disponível em: http://rbep.inep.gov.br/ojs3/index.php/rbep/article/view/4363. Acesso em: 19 jun. 2020.

DELORME, M. I. de C. Experiências criadoras na(s) infância(s). Veras, São Paulo, v. 8, n. 2, p. |6| - |82, jul./dez. 2018. Disponível em: https://site.veracruz.edu.br/instituto/revistaveras/index.php/revistaveras/article/view/328. Acesso em: 19 jun. 2020.

DORNELLES, L. V.; BUJES, M. I. E. Educação e Infância na era da informação. Porto Alegre: Mediação, 2012.

FLACH, F.; SORDI, R. O. A Educação Infantil escolar como espaço de subjetivação. Estilos da Clínica, São Paulo, v. XII, n. 22, p. 80-99, 2007. Disponível em: http://www.revistas.usp.br/estic/article/view/46019. Acesso em: 19 jun. 2020.

FRANCO, A. De Caçador a Gourmet. São Paulo: Editora Senac, 2004.

FOUCAULT, M. O Sujeito e o Poder. In: DREYFUS, H. L.; RABINOW, P. Michel Foucault: uma trajetória filosófica. Rio de Janeiro: Forense Universitária, 1995.

FOUCAULT, M. O nascimento da Biopolítica. São Paulo: Martins Fontes, 2008.

FOUCAULT, M. Vigiar e punir: o nascimento das prisões. Petrópolis, RJ: Vozes, 2014. 
GUIMARÃES, D. Relações entre bebês e adultos na creche: o cuidado como ética. São Paulo: Cortez, 2011 .

HORN, M. da G. S. A ética e o cuidado com a alimentação na escola infantil. Pátio Educação Infantil, Porto Alegre, n. 47, abril 20 16. Disponível em: https://www.grupoa.com.br/ciencias-humanas/revistaspatio. Acesso em: 14 set. 2019.

KRAMER, S. Precisamos estar preparados para brincar muito. Entrevista. Revista Interinstitucional Artes de Educar, Rio de Janeiro, v. 6, n. 2, p. 775-791, maio/ago. 2020. Disponível em: https://www.epublicacoes.uerj.br/index.php/riae/article/view/51073/0. Acesso em: 19 jun. 2020.

KRAMER, S. Autoria e autorização: questões éticas na pesquisa com crianças. Cadernos de pesquisa, São Paulo, n. I 16, p. 4I-59, julho 2002. Disponível em:

http://publicacoes.fcc.org.br/ojs/index.php/cp/article/view/556. Acesso em: 19 jun. 2020.

LARROSA, J. Tecnologias do eu e educação. In: SILVA, T. T. (Org.). O sujeito da educação. Estudos foucaultianos. Petrópolis: Vozes, 1994. p.35-86.

LIMA, R. de S.; NETO, J. A. F.; FARIAS, R. de C. P. Alimentação, comida e cultura: o exercício da comensalidade. Demetra: alimentação, nutrição \& saúde, Rio de Janeiro, v. 10, n. 3, p. 507-522, 2015. Disponível em: https://www.e-publicacoes.uerj.br/index.php/demetra/article/view/I 6072. Acesso em: 19 jun. 2020.

LOURO, G. Gênero, sexualidade e educação. Uma perspectiva pós-estruturalista. 6 ed. Petrópolis, RJ: Vozes, 1997.

MACIEL, M. E. Cultura e alimentação ou o quê tem a ver os macaquinhos de Koshima com BrillatSavarin? Horizontes Antropológicos, Porto Alegre, ano 7, n. 6, p. 145- 156, dez. 200 I. Disponível em: https://www.scielo.br/pdf/ha/v7n 16/v7n 16a08.pdf. Acesso em: 19 jun. 2020.

MESOMO, A. C. Educação Infantil: indagando sobre práticas escolarizante. Orientador: Cecília Hanna Mate. 9 If. 2004. Dissertação (Mestrado em Educação) - Universidade de São Paulo, USP, São Paulo, 2004.

PIOTTO, D. C.; FERREIRA, M. V.; PANTONI, R. V. "Comer, comer...comer, comer...é o melhor para poder crescer...". In: ROSSETTI-FERREIRA, M. C. (Org.). Os fazeres na Educação Infantil. São Paulo: Cortez, 2006. p. $126-128$.

QUIJANO, A. Colonialidad del poder, eurocentrismo y América Latina. In: LANDER, E. (Org.). La colonialidad del saber: eurocentrismo y ciencias sociales. Perspectivas latinoamericanas. Buenos Aires: CLACSO, 2000. p. 201-249.

ROSE, N. Inventando nossos eus. In: SILVA, T. T. (Org.). Nunca fomos humanos. Belo Horizonte: Autêntica, 200 I. p. I37-204.

SANTIAGO, F. "O meu cabelo é assim... igualzinho o da bruxa, todo armado". Hierarquização e racialização das crianças pequenininhas negras na educação infantil. Dissertação (Mestrado em Educação), Universidade Estadual de Campinas, Faculdade de Educação, Campinas, SP, 2014.

VEIGA-NETO, A. Por que governar a infância? In: RESENDE, H. de (Org.). Michel Foucault. O governo da infância. Belo Horizonte: Autêntica, 20 15. p. II - 24. 
VITOR, T. C.; LIRA, A. C. M. A Educação Infantil e os momentos de alimentação: uma análise do que é praticado, com ênfase nas relações estabelecidas. In: RIBEIRO, D.; DOMINICO, E.; NUNES, M. A. (Orgs.). Tecendo olhares e debates na Educação Infantil: políticas educacionais, diversidade e práticas pedagógicas. Guarapuava: Apprehendere, 2019. p. II2-130.

\section{COMO CITAR ESSE ARTIGO}

MESOMO LIRA, Aliandra Cristina et al. "Princesa come de boca fechada": reflexões foucaultianas sobre as práticas alimentares na Educação Infantil. Debates em Educação, Maceió, v. 12, n. 28, p. 95- I |4, Set./Dez. 2020. ISSN 2175-6600. Disponível em:

https://www.seer.ufal.br/index.php/debateseducacao/article/view/9l81. Acesso em: dd mmm. aaaa. 